\title{
ANALISIS SIFAT MEKANIS PROPELER PERAHU NELAYAN TRADISIONAL BERBAHAN ALUMINIUM
}

\author{
Suyanto $^{1 *}$, Imam Syafaat ${ }^{2}$ \\ ${ }^{1}$ Jurusan Teknik Bangunan Kapal, Akademi Teknik Perkapalan Veteran \\ Jl. Pawiyatan Luhur IV No. 18 Bendan Dhuwur, Semarang 50235 \\ ${ }^{2} J u r u s a n$ Teknik Mesin, Fakultas Teknik, Universitas Wahid Hasyim \\ J1. Menoreh Tengah X/22, Sampangan, Semarang 50236 \\ "Email : suyantoeste@yahoo.com
}

\begin{abstract}
Abstrak
Nelayan tradisional di pantai utara Jawa Tengah banyak yang menggunakan propeler dengan bahan aluminium tuang sebagai penggerak kapal kayu, dengan pertimbangan harga yang murah. Pada umumnya propeler yang digunakan tidak berumur lama. Kerusakan yang paling banyak terjadi adalah patah pada daun propeler Hal ini disebabkan adanya benturan dengan benda keras. Penelitian ini dilakukan untuk mengetahui komposisi dan sifat mekanis aluminium sebagai bahan propeler. Pengujian yang dilakukan meliputi uji komposisi, uji densitas, uji kekerasan, uji tarik, dan struktur mikro. Hasil uji komposisi menunjukkan adanya unsur paduan dominan berupa $\mathrm{Si}, \mathrm{Zn}$, dan Fe. Nilai porositas yang dimiliki bahan adalah 7\%. Sementara itu kekerasan rata-rata bahan adalah 83,6 BHN, kekuatan tarik sebesar 139,2 $M P a$, dan \%EL sebesar 2,48\%. Keberadaan unsur Fe dan Zn menyebabkan nilai kekerasan Aluminium meningkat. Nilai porositas yang cukup tinggi menyebabkan aluminium bersifat getas.

Kata kunci : Aluminium, Propeler, Perahu, Tradisional
\end{abstract}

\section{PENDAHULUAN}

Nelayan tradisional di pantai utara Jawa Tengah banyak menggunakan propeler dengan bahan aluminium tuang sebagai penggerak kapal kayu mereka. Pemakaian propeler aluminium ini dikarenakan harganya yang murah. Bahan propeler standar yang biasa digunakan adalah kuningan. Namun di pasaran untuk tipe propeler yang sama harganya mencapai 20 kali lebih mahal dibanding propeler berbahan aluminium. Inilah alasan utama kenapa nelayan tradisional di pantai utara Jawa Tengah rata-rata menggunakan propeler aluminium.

Hal yang menarik untuk dikaji adalah performansi propeler aluminium terutama dari hal ketahanan atau keawetan sangat rendah. Rata-rata usia pemakaian propeler aluminium tidak lebih dari satu bulan. Bahkan ada yang sekali hingga dua kali dipakai melaut propeler sudah patah. Dari data di lapangan didapatkan bahwa kerusakan propeler yang terjadi didominasi oleh kondisi patah pada salah satu atau beberapa daunnya. Sedangkan faktor kerusakan karena korosi tidak dominan. Patah pada daun propeler disebabkan oleh adanya benturan daun propeler dengan benda keras yang ada di perairan dangkal seperti bebatuan. Kondisi patah yang dialami propeler aluminium bisa dilihat pada Gambar 1.
Gambar 1. (a) menunjukkan bahwa salah satu daun propeler mengalami patah.

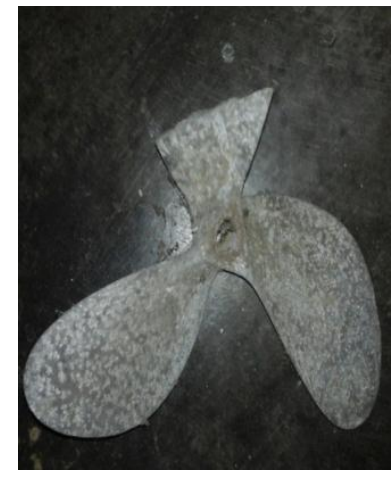

(a)

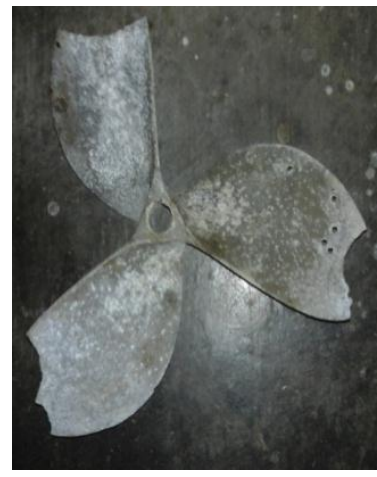

(b)
Gambar 1. (a) Propeler mengalami patah pada salah satu daunnya, (b) mengalami patah pada tiap ujung daunnya dan lubanglubang pada daunnya

Kondisi ini terjadi pada propeler aluminium dengan pemakaian antara 1 sampai dengan 2 minggu pada kondisi nelayan melaut setiap hari. Jika dilihat sekilas pada bentuk perpatahan dan kondisi lingkungan pemakaian maka patah yang terjadi adalah patah getas akibat daun propeler bertumbukan dengan benda keras. Pada gambar 1. (b) bisa dilihat bahwa terjadi patah pada ujung tiap daun propeler dan terdapat lubang-lubang pada daun 
propeler. Kondisi ini terjadi pada pemakaian propeler lebih dari 1 bulan pada kondisi nelayan melaut setiap hari. Cacat patah yang terjadi diperkiraan karena benturan daun propeler dengan benda keras, sehingga propeler dengan bahan aluminium cor dengan sifat getas mengalami patah getas. Lubang-lubang yang terjadi pada daun propeler mengindikasikan terjadinya korosi kavitasi.

Aluminium dan paduannya pada dasarnya memiliki sifat ringan dan tahan terhadap korosi. Kekuatan dan kekerasan paduan aluminium tertentu juga tergolong tinggi. Sebagai contoh aluminium paduan yang biasa digunakan untuk bahan propeler maupun impeler adalah ADC3 dengan unsur pemadu utama Si 8\%-10,5\% dan Mg 0,17-0,3\%. ADC 3 mempunyai sifat mekanik dengan kekuatan tarik $317 \mathrm{MPa}$, kekuatan luluh $170 \mathrm{MPa}$, persen perpanjangan 3,5\%, kekerasan $75 \mathrm{BHN}$ dan Modulus Young $71 \mathrm{GPa}$. ADC 3 mempunyai sifat ketahanan impak yang baik, serta tahan korosi, sehingga biasa digunakan untuk propeler kapal dengan motor tempel (NADCA, 2009).

Pengujian pada propeler aluminium yang digunakan oleh nelayan tradisional perlu di lakukan untuk mengetahui sifat mekanis yang dimilikinya, termasuk di dalamnya kekuatan, keuletan, kekerasan, dan kekakuannya. Sifat tersebut kemudian dijadikan dasar untuk penilaian dan membandingkannya dengan sifat mekanis material standar, merujuk pada ASM Handbook. Akan diketahui apakah material propeler aluminium tersebut sesuai atau tidak dengan standar ASM (ASM, 1992).

Setiawan (2014) meneliti komposisi dan kekerasan produk propeler berbahan aluminium yang diproduksi oleh UMKM di Juwana Pati. Hasil penelitian menunjukkan kekerasan bahan rata-rata adalah 60,5 HRB dan komposisi bahan yang dominan adalah $\mathrm{Al}, \mathrm{Cu}, \mathrm{Pb}, \mathrm{Si}$, dan $\mathrm{Fe}$.

Penelitian tentang remelting bahan aluminium yang menggunakan bahan ADC 12 juga pernah dilakukan. Dihasilkan kesimpulan bahwa remelting pada aluminium dapat menyebabkan penurunan kekerasan material, dan meningkatkan porositas (Raharjo dkk., 2011).

Berbagai penelitian telah dilakukan, namun belum terlihat penelitian yang menyeluruh terhadap sifat mekanis propeler. Penelitian ini bertujuan untuk mengetahui komposisi dan sifat mekanis aluminium sebagai bahan propeler. Pengujian yang dilakukan meliputi uji komposisi, uji densitas, uji kekerasan, uji tarik, dan struktur mikro.

\section{METODOLOGI PENELITIAN}

Penelitian yang dilakukan untuk mengetahui sifat mekanis propeler aluminium ini dilakukan dengan urutan pemilihan material propeler, pembuatan spesimen uji, pengujian komposisi, pengujian densitas, pengujian sifat mekanis, serta foto struktur mikro. Uji sifat mekanis yang dilakukan meliputi uji kekerasan dan uji tarik.

\subsection{Pemilihan Material dan Spesimen}

Material yang dipilih untuk pengujian adalah propeler aluminium berdiameter 300 mm yang digunakan untuk mesin kapal 22-25 PK. Spesimen dibuat dari tiga buah propeler, dengan masing-masing propeler diambil bagian pangkal, tengah, serta ujung daunnya. Dengan pemilihan material dan spesimen seperti itu diharapkan hasil pengujian bisa memberikan data yang tepat. Pembagian area daun propeler bisa dilihat pada Gambar 2 .

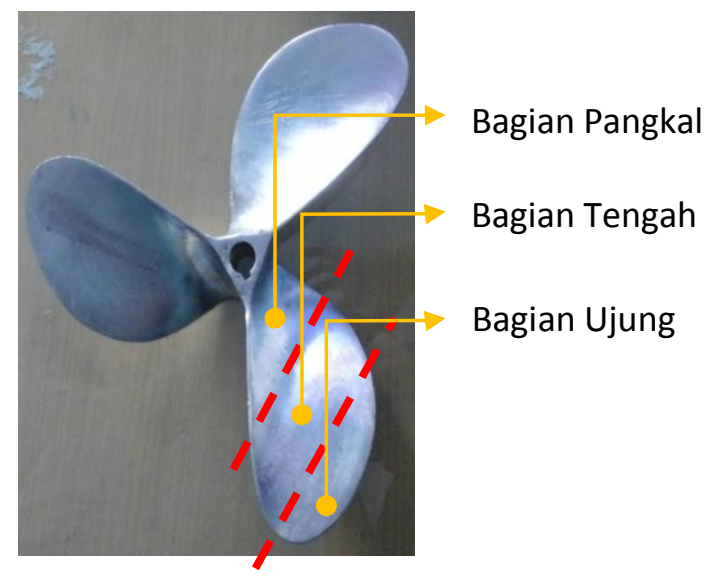

\section{Gambar 2. Posisi pengambilan spesimen}

Bagian pangkal adalah jarak $0 \mathrm{~mm}$ sampai dengan $50 \mathrm{~mm}$ dari sumbu propeler. Bagian tengah adalah jarak $50 \mathrm{~mm}$ sampai dengan $100 \mathrm{~mm}$ dari sumbu propeler. Bagian ujung adalah jarak $100 \mathrm{~mm}$ sampai dengan 150 $\mathrm{mm}$ dari sumbu propeler.

\subsection{Uji Komposisi}

Uji Komposisi dilakukan untuk mengetahui komposisi kimia material propeler. Pengujian yang dilakukan menggunakan alat uji spectrometer di Laboratorium Metalurgi Politeknik Manufaktur Ceper, Klaten. Spesimen uji komposisi dibuat kecil dengan ukuran sekitar $20 \mathrm{~mm}$ dan ketebalan 10 sampai $20 \mathrm{~mm}$. 


\subsection{Uji Densitas}

Uji densitas dilakukan untuk mengetahui berapa besar densitas atau masa jenis bahan propeler. Untuk mendapatkan nilai porositas dilakukan perhitungkan dengan membandingkan nilai densitas material hasil pengukuran dengan densitas teoritis material. Spesimen yang sudah dipotong dari propeler kemudian dilakukan penimbangan pada neraca digital untuk mendaptakn masa kering spesimen. Dilanjutkan dengan penimbangan spesimen di dalam air untuk mendapatkan masa basah. Data yang diperoleh kemudian dimasukkan ke dalam Persamaan (1).

$\rho_{\text {apparent }}=\rho_{H 2 O} x \frac{M_{d r y}}{M_{\text {dry }}-M_{\text {wet }}}$

$\rho_{\text {apparent }}$ adalah masa jenis spesimen, $\rho_{\text {H2O }}$ adalah masa jenis air, $\mathbf{M}_{d r y}$ adalah masa spesimen ditimbang dalam konsisi kering, dan $\mathrm{M}_{\text {wett }}$ adalah masa spesimen ditimbang dalam air.

Harga porositas spesimen didapatkan dengan metode rule of mixture menggunakan Persamaan (2).

$\% P=\left(1-\frac{\rho_{s}}{\rho_{\text {th }}}\right) \times 100 \%$

$\% P$ adalah persentase porositas, $\rho_{s}$ adalah ensitas hasil pengukuran $\left(\mathrm{gr} / \mathrm{cm}^{3}\right)$, dan $\rho_{t h}$ densitas teoritis $\left(\mathrm{gr} / \mathrm{cm}^{3}\right)$

\subsection{Uji Kekerasan}

Pengujian kekerasan dilakukan dengan uji kekerasan Brinell. Identon dikenakan pada permukaan penampang potongan melintang dari daun propeler. Spesimen di-mounting terlebih dahulu, karena ukuran spesimen yang kecil, dengan tujuan memudahkan proses pengujian. Sebelum diuji, spesimen diamplas untuk mendapatkan permukaan yang rata.

\subsection{Uji Tarik}

Pengujian tarik dilakukan untuk mengetahui kekuatan tarik, keuletan, serta kekakuan material. Pelaksanaan uji tarik berdasarkan standar ASTM E-8M, spesimen dengan panjang ukur $25 \mathrm{~mm}$, lebar $6 \mathrm{~mm}$ dan tebal $3 \mathrm{~mm}$, seperti pada Gambar 3.

\subsection{Uji Struktur Mikro}

Pengujian struktur mikro dilakukan dengan mikroskop optik, dilakukan untuk mengetahui bentuk dan ukuran butir. Dengan uji struktur mikro juga bisa diketahui susunan butir yang ada, serta porositas yang ada pada spesimen. Uji struktur mikro dilakukan dengan urutan pemotongan spesimen, pengamplasan, pemolesa, pencelupan dalam cairan etsa berupa $\mathrm{HF}$, dan melihat struktur mikro dengan mikroskop optik.

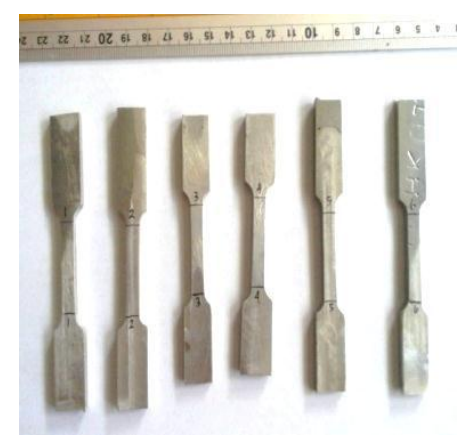

\section{Gambar 3. Spesimen uji tarik standar ASTM E-8M}

\section{HASIL DAN PEMBAHASAN}

\subsection{Hasil Uji Komposisi}

Uji komposisi dilakukan di Laboratorium Pengujian Logam Politeknik Manufaktur Ceper dengan alat Spectrometer Metal Scan, dengan hasil seperti Tabel 1.

\section{Tabel 1. Komposisi bahan propeler}

\begin{tabular}{cccccccc}
\hline Unsur & $\mathrm{Al}$ & $\mathrm{Si}$ & $\mathrm{Fe}$ & $\mathrm{Cu}$ & $\mathrm{Mn}$ & $\mathrm{Cr}$ & $\mathrm{Zn}$ \\
\hline $\begin{array}{c}\text { Komposisi } \\
(\%)\end{array}$ & 85,82 & 7,51 & 1,08 & 0,12 & 0,19 & 0,12 & 4,78 \\
\hline
\end{tabular}

Jika dilihat komposisi material, maka unsur dominan yang ada yaitu Al 85,82\%, kemudian Si 7,51\%, Fe 1,08\%, dan Zn 4,78\%. Komposisi tersebut jika dibandingkan dengan komposisi Aluminium paduan standar ASM, maka akan mempunyai kemiripan dengan aluminium paduan seri A356.0. Aluminium paduan ini mempunyai unsur utama yitu $\mathrm{Si}$ 6,5\%-7,5\%, Fe 0,6\%, Mg 0,25\% - 0,45\%, dan Zn 0,35\% (ASM, 1992). Perbedaan yang mencolok antara dua aluminium paduan di atas adalah pada unsur Zn. Material A356 standar hanya mengandung $\mathrm{Zn}$ sekiar $0,35 \%$, sedangkan hasil uji komposisi material propeler menunjukkan kandung $\mathrm{Zn}$ yang ada sebesar 4,78\%. Kehadiran $\mathrm{Zn}$ dengan prosentase cukup 
besar ini tentunya akan berpengaruh pada sifat mekanis material.

Karakteristik material aluminium paduan yang tergolong dalam seri A3xx.x diantaranya mempunyai mampu laku panas yang baik, bisa dilakukan pengecoran dengan cetakan pasir, cetakan permanen, maupun die casting. Sifat mampu alir dari A3xx.x tergolong baik, sifat mekanis berupa kekuatan dan keuletan yang tinggi, serta mampu las yang baik. Kekuaertan tarik yang dimiliki material A3xx.x berkisar 19 - $40 \mathrm{ksi}$ atau 130-274 $\mathrm{MPa}$ (Handbook of Material Selection, 2002).

Aluminium seri A3xx.x banyak digunakan dalam industri pengecoran. Beberapa alasan dalampenggunaannya diantaranya adalah karena mempunyai mampu alir yang sangat baik. Sifat tersebut dipengaruhi oleh kandungan unsur $\mathrm{Si}$ dalam aluminium. Kadar $\mathrm{Si}$ dalam aluminium bisa dibuat dalam persentase rendah hingga tinggi. Dengan mampu alir yang baik akan bisa dihasilkan produk yang mempunyai bentuk komplek. Disamping itu produksi A3xx.x yang bisa mengunakan bahan daur ulang aluminium scrap juga menjadi pertimbangan utama.

Kandungan $\mathrm{Fe}$ pada bahan aluminium propeler tergolong tinggi, yaitu sebesar $1,08 \%$. Kehadiran $\mathrm{Fe}$ ini akan memicu terbentuknya ikatan $\mathrm{Al} 5 \mathrm{FeSi}$ yang berpengaruh terhadap bentuk butir dan sifat mekanis bahan (Dash dan Makhlouf, 2001).

\subsection{Hasil Uji Densitas}

Nilai densitas dan porositas pada masingmasing bagian propeler mempunyai perbedaan nilai, seperti terlihat pada Tabel 2 dan Gambar 4. Dari hasil perhitungan, porositas tertinggi dimiliki daun propeler bagian pangkal dengan nilai porositas $8,3 \%$. Bagian ini mempunyai posisi terdekat dengan saluran tuang. Adapun porositas terendah dimiliki daun propeler bagian tengah dengan nilai porositas 5,3\%. Porositas $(\mathrm{P})$ rata-rata keseluruhan bagian propeler adalah $7 \%$. Porositas hasil penelitian ini hampir sama dengan penelitian Krisnawan dkk. (2012), yang meneliti pengecoran aluminium dengan bahan aluminium bekas piston dan cetakan pasir. Nilai porositas yang diperoleh berkisar 5,10\% - 8,89\%. Penelitian tentang pengecoran aluminum dengan cetakan pasir (Hendronursito dan Prayanda, 2016), menghasilkan nilai porositas antara 5,08\% $6,98 \%$.
Penelitian dengan melakukan pengecoran ulang aluminium bekas sepatu rem motor dengan cetakan pasir yang dilakukan Sudibyo dkk. (2013) mendapatkan hasil pengecoran dengan nilai porositas $1,93 \%$ - 2,63\%. Penelitian serupa dilakukan oleh Pratiwi (2012) dengan melakukan pengecoran dengan bahan aluminium skrap dengan cetakan pasir menghasilkan produk dengan nilai porositas $0,3 \%-1 \%$.

Tabel 2. Data densitas dan porositas daun propeler

\begin{tabular}{cll}
\hline BLADE & POSISI & \% P \\
\hline \multirow{3}{*}{ BLADE 1} & Pangkal & $8 \%$ \\
& Tengah & $6 \%$ \\
& Ujung & $7 \%$ \\
\hline \multirow{3}{*}{ BLADE 2} & Pangkal & $8 \%$ \\
& Tengah & $5 \%$ \\
& Ujung & $6 \%$ \\
\hline \multirow{3}{*}{ BLADE 3 } & Pangkal & $9 \%$ \\
& Ujung & $5 \%$ \\
& Tengah & $7 \%$ \\
\hline Rata-Rata & & $7 \%$ \\
\hline
\end{tabular}

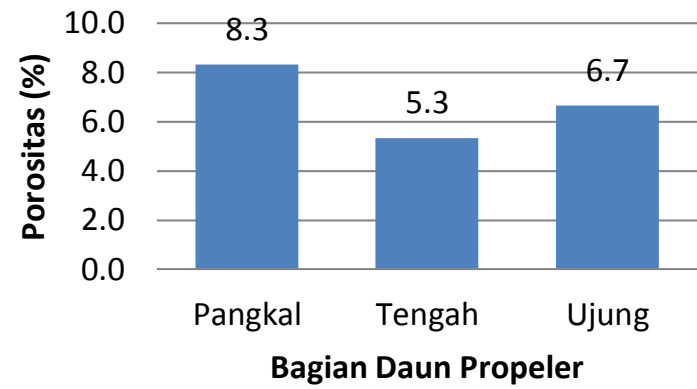

\section{Gambar 4. Hubungan Tingkat Porositas dengan Bagian Daun Propeler}

Kesimpulan yang bisa diambil dengan membandingkan nilai porositas propeler hasil perhitungan dan hasil penelitian terdahulu, maka nilai porositas propeler dalam penelitian ini tergolong tinggi.

3.3. Hasil Uji Kekerasan

Tabel 3. Data kekerasan bagian propeler

\begin{tabular}{clc}
\hline BLADE & POSISI & H (BHN) \\
\hline \multirow{3}{*}{ BLADE 1 } & Pangkal & 74,9 \\
& Tengah & 86,7 \\
& Ujung & 85,2 \\
\hline \multirow{3}{*}{ BLADE 2 } & Pangkal & 75,1 \\
& Tengah & 94,6 \\
& Ujung & 92,3 \\
\hline \multirow{2}{*}{ BLADE 3 } & Pangkal & 75,7 \\
& Ujung & 84,7
\end{tabular}




\begin{tabular}{lll} 
& Tengah & 83,1 \\
\hline Rata-Rata & & 83,6 \\
\hline
\end{tabular}

Kekerasan bahan propeler aluminium dari hasil pengujian bisa dilihat pada Tabel 3 . Rata-rata kekerasan hasil pengujian adalah 83,6 BHN. Nilai ini lebih tinggi jika dibandingkan dengan kekerasan A356 Standar yaitu 60 -75 BHN (ASM, 1992). Nilai kekerasan yang lebih tinggi ini dipengaruhi oleh adanya unsur $\mathrm{Fe}$ dan Zn. Kandungan Fe 1,08\%, dan Zn 4,78\% adalah persentase yang cukup besar untuk berpengaruh pada sifat mekanis bahan AlSi. Penambahan $\mathrm{Zn}$ pada aluminium paduan dapat meningkatkan kekerasan, terutama setelah proses precipitation hardening (Sofyan dkk., 2008). Pengaruh unsur $\mathrm{Fe}$ dalam bahan AlSi pernah diteliti Hendra dan Husmadi (2013) yang menggunakan bahan AlSi11\% dengan penambahan $\mathrm{Fe}$ 0\%-1\%. Dinyatakan bahwa semakin banyak penambahan $\mathrm{Fe}$, makan kekerasan akan meningkat.

\subsection{Hasil Uji Tarik}

Tabel 4. Data Kekuatan Tarik dan \%EL

\begin{tabular}{ccc} 
SPESIMEN & $\boldsymbol{\sigma} \boldsymbol{u}(\boldsymbol{M P a})$ & EL $(\boldsymbol{\%})$ \\
\hline 1 & 135 & 2,1 \\
2 & 153 & 2,5 \\
3 & 137 & 2,9 \\
4 & 135 & 2,3 \\
5 & 136 & 2,6 \\
\hline RATA-RATA & $\mathbf{1 3 9 , 2}$ & $\mathbf{2 , 4 8}$ \\
\hline
\end{tabular}

Data pada Tabel 4 menunjukkan bahwa bahan propeler aluminium mempunyai kekuatan tari rata-rata $139,2 \mathrm{MPa}$ dan \%EL rata-rata $2,48 \%$. Jika dibandingkan dengan material standar A356 yang mempunyai kekuatan tarik $172 \mathrm{MPa}-234 \mathrm{MPa}$ (ASM, 1992). Hasli pengujian tarik material propeler aluminium menunjukkan harga yang lebih rendah $18 \%$. Kekuatan tarik yang lebih rendah disebabkan oleh adanya porositas yang cukup tinggi pada hasil pengecoran. Pengecoran ulang pada aluminium scrap juga berpengaruh pada penurunan kekuatan tarik aluminium. Keuletan material ditunjukkan oleh nilai \%EL, dimana nilai rata-rata \%EL material aluminium propeler adalah $2,48 \%$. Harga tersebut adalah harga yang umum dimiliki oleh bahan aluminium terutama A356, dimana \%EL aluminium standar dengan cetakan pasir adalah
$2-3,5 \%$ (ASM, 1992), yang memiliki sifat getas.

\subsection{Hasil Uji Struktur Mikro}

Struktur Mikro bahan propeler aluminium dengan kandungan $\mathrm{Al} 85,82 \%, \mathrm{Si}$ 7,5\%, Fe 1,08\%, dan Zn 4,78\% bisa dilihat pada Gambar 5(a). Pada gambar terlihat bahwa bahan masih memiliki struktur mikro dendritik yang halus. Hal ini sesuai dengan literatur yang menyatakan bahwa penambahan unsur $\mathrm{Zn}$ akan memperhalus dendrit pada paduan aluminium cor (ASM, 1992).
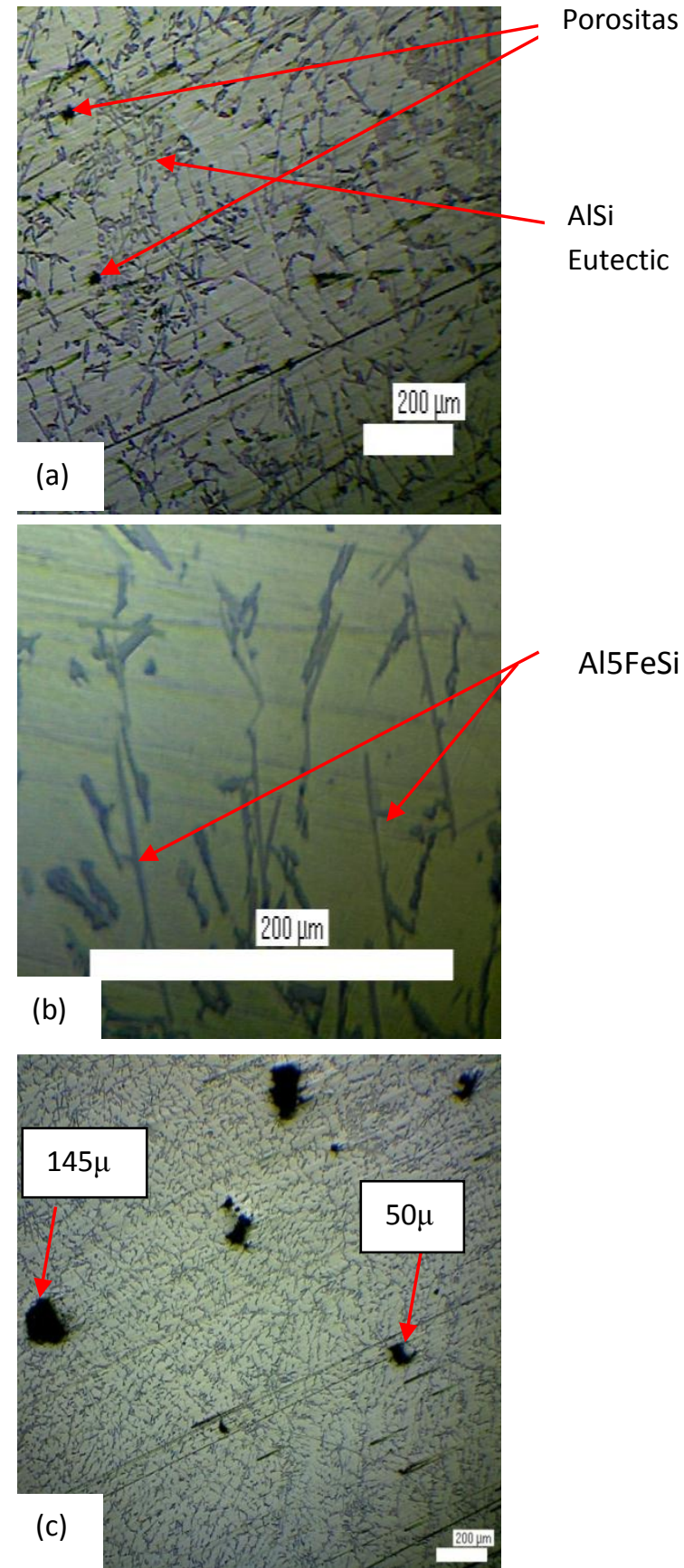


\section{Gambar 5. (a) Struktur AISi Eutectic dengan bentuk dendrit (b) Struktur Al5FeSi berbentuk jarum (c) Ukuran porositas}

Dendrit yang terbentuk adalah $\mathrm{AlSi}$ eutectic yang mempunyai bentuk struktur menyerupai huruf China, Gambar 5(b). Sementara itu kehadiran $\mathrm{Fe}$ akan memicu terbentuknya ikatan $\mathrm{A} 15 \mathrm{FeSi}$ yang berpengaruh terhadap bentuk butir dan sifat mekanis bahan (Dash dan Makhlouf, 2001).

Betuk struktur dari $\mathrm{Al} 5 \mathrm{FeSi}$ adalah menyerupai jarum panjang. $\alpha$-Al tampak sebagai bagian yang terang. Struktur ini merupakan bagian mayoritas yang nampak pada foto mikro. Porositas yang ada terlihat sebagai lubang -lubang hitam yang tersebar secara acak. Porositas pada material propeler aluminium dengan nilai rata-rata $7 \%$ nampak sebagai lubang hitam pada foto mikro dengan ukuran antara 50 hingga 145 mikrometer, seperti terlihat pada Gambar 5(c).

\section{KESIMPULAN}

Dari penelitian yang dilakukan terhadap propeler dengan bahan aluminium dapat disimpulkan sebagai berikut :

1. Bahan mempunyai komposisi unsur dominan Al 85,82\%, Si 7,51\%, Fe 1,08\%,

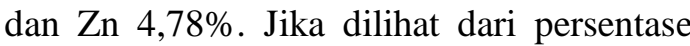
unsur $\mathrm{Al}$ dan $\mathrm{Si}$ komposisi material ini mendekati aluminium A356.

2. Bahan mempunyai nilai porositas rata-rata $7 \%$. Nilai porositas ini tergolong tinggi.

3. Kekerasan rata-rata dari bahan adalah 83,6 BHN, lebih tinggi dibandingkan dengan Aluminium A356. Hal tersebut disebabkan oleh adanya unsur Fe dan Zn.

4. Kekuatan tarik bahan adalah 139,2 MPa, lebih rendah dari kekuatan tarik aluminium A356. Hal ini disebabkan oleh adanya nilai porositas yang tinggi.

5. Bahan propeler termasuk getas dengan $\%$ EL sebesar 2,48\%.

\section{DAFTAR PUSTAKA}

ASM Handbook Vol. 2, (1992), Properties and Selection Nonferrous Alloy and SpecialPurpose Materials, ASM International.

Dash, M., Makhlouf, M., (2001), Effect of key alloying elements on the feeding characteristics of aluminum-silicon casting alloys, Journal of Light Metals 1 , pp. 251-265.

Handbook of Material Selection, (2002), Chapter 4 : Aluminum Alloys, John Wiley and Sons Inc; New York.

Hendra, Husmadi, (2013), Pengaruh Penambahan Fe Terhadap Sifat Mekanik dan Struktur Mikro pada Paduan Al$11 \% \mathrm{Si}$, Thesis, Universitas Andalas.

Hendronursito, Y., Prayanda, Y., (2016), Potensi Pasir Lokal Tanjung Bintang pada Aluminium Sand Casting terhadap Porositas Produk Hasil Cor Aluminium, Jurnal Kajian Teknik Mesin Vol. 2 No. 2 , pp. 60-68.

Krisnawan, H., Kusharjanta, B., Raharjo, WP., (2012), Pengaruh Ukuran Riser Terhadap Cacat Penyusutan dan Cacat Porositas Produk Cor Aluminium Cetakan Pasir, Mekanika Vol. 10 No. 2, pp. 125-130.

NADCA, (2009), Product Specification Standards for Die Castings.

Pratiwi, DK., (2012), Hubungan Jenis Cetakan Terhadap Kualitas Produk Cor Aluminium, Prosiding SNTTM XI \& Thermofluid IV Universitas Gadjah Mada, pp. 1846-1851.

Raharjo, S., Abdillah, F., Wanto, Y., (2011), Analisa Pengaruh Pengecoran Ulang Terhadap Sifat Mekanik Paduan Alumunium ADC 12, Prosiding SNST Unwahas, pp. D106-D111.

Setiawan, H., (2014), Pengujian Kekerasan dan Komposisi Kimia Produk Cor Propeler Aluminium, Prosiding SNST ke-5 Unwahas, pp. 31-36.

Sofyan, BT., Susanti, S., Yusfranto, RR., (2008), Peran 1 dan 9 w.t.\% Zn dalam Proses Pengerasan Presipitasi Paduan Aluminium AA319, Makara Teknologi, 12 (1), pp. 48-54.

Sudibyo, A., Kusharjanta, B., Raharjo, WP., (2013), Pengaruh Penampang Ingate terhadap Cacat Porositas dan Nilai Kekerasan pada Proses Pengecoran Aluminium Menggunakan Cetakan Pasir, Mekanika Vol. 12 No. 1, pp. 53-56. 